\title{
Indicadores para evaluar la eficiencia de programas sociales. Una propuesta a partir de un Proyecto de Aprendizaje-Servicio entre alumnos de la Facultad de Derecho de la UNED y el Ayuntamiento de Madrid
}

\section{Miryam C. González Rabanal'}

Resumen: Este trabajo recoge los resultados de un Proyecto de Aprendizaje-Servicio (ApS) vinculado con los Objetivos de Desarrollo Sostenible (ODS): 4, 10, 11, 12 y 16, desarrollado en el curso 2019-20² con estudiantes de la Facultad de Derecho de la UNED y el Ayuntamiento de Madrid.

Se ha seguido una metodología cualitativa y de meta-síntesis cualitativa.

El servicio del ApS consistió en la propuesta de 48 indicadores, agrupados en 5 categorías, para evaluar el Plan Operativo Contra la Trata y otros Abusos de Derechos Humanos en contextos de prostitución. El aprendizaje del Proyecto ha completado la formación de los alumnos sobre indicadores para evaluar programas sociales.

Palabras clave: Aprendizaje-Servicio; Indicadores; Evaluación de programas; Enseñanza a distancia; ODS; Innovación pedagógica; Educación superior.

Fecha de recepción: I de febrero de 202I.

Fecha de admisión definitiva: 20 de abril de 2021 .

' Departamento de Economía Aplicada y Gestión Pública. Facultad de Derecho. Universidad Nacional de Educación a Distancia (UNED). ORCID ID: https://orcid.org/0000-0002-4173-9755

${ }^{2}$ Este Proyecto se ha realizado al amparo de la II Convocatoria de Proyectos de Innovación Docente (2019-20) del Instituto Universitario de Educación a Distancia (IUED) de la UNED y con la colaboración de la Dirección General de Innovación y Estrategia Social del Ayuntamiento de Madrid. 
Indicators to assess the efficiency of social programs. A proposal based on a Service-Learning Project among students of the Faculty of Law of UNED and the City Council of Madrid

Abstract: This paper presents the results of a Service-Learning project (S-L) relating to Sustainable Development Goals (SDG) 4, $10,11,12$ and 16 . The project was run by students of the UNED Faculty of Law and the Madrid City Council during the academic year 2019-2020.

The methodology applied followed a qualitative and a qualitative meta-synthesis approach.

The service aspect of the S-L project consisted in proposing 48 indicators, grouped into 5 categories, as a tool to assess the Operational Plan to Combat Human Trafficking and other Human Rights Abuses in the Context of Prostitution. The lessons drawn from the project completed the students' training in indicators used to assess social programmes.

Key words: Service-Learning; indicators; programme assessment; program assessment, distance learning; SDG; pedagogical innovation; higher education.
Indicateurs pour évaluer l'efficacité des programmes sociaux. Proposition basée sur un Projetd'Apprentissage par le Service réalisé par des étudiants de la faculté de droit de I'UNED et le Conseil Municipal de Madrid

Résumé: Ce travail rassemble les résultats $d$ 'un projet $d$ 'apprentissage par le service (A.P.S) lié aux objectives de développement durable $4,10,11,12$ et 16 , réalisé par des étudiants de la faculté de droits de I'UNED etle conseil municipal de Madrid en 2019-2020.

Une méthodologie qualitative et de métasynthèse qualitative a été suivie.

Le service du projet A.P.S. a consisté à proposer 48 indicateurs, regroupés en 5 catégories, pour évaluer le Plan Opérationnel pour Combattre le Trafic Humain etautres Violations des Droits Humains dans le Contexte de la Prostitution. Ce qui a été appris dans le cadre du projet a complété la formation des élèves en matière $d$ 'indicateurs d'évaluation des programmes sociaux.

Mots clé: apprentissage par le service; indicateurs; évaluation de programmes; enseignement à distance; ODD; innovation pédagogique; éducation supérieure.

\section{Introducción}

La puesta en marcha del Espacio Europeo de Educación Superior (EEES) ha comportado la necesidad de que las universidades incorporaran a su forma tradicional de enseñar nuevas metodologías orientadas a la formación en competencias generales y específicas de sus estudiantes y que se preocuparan también por la trasmisión de valores más allá de los estrictos conocimientos que integran el contenido de cada disciplina. Con estos propósitos han tomado auge las propuestas de aprendizaje experiencial y/o colaborativo y las que otorgan relevancia a la educación en valores. 
La gran ventaja del ApS es que responde a una necesidad de la comunidad y contribuye a conseguir una educación de calidad, vinculada a valores de interés social, y a elementos de aprendizaje que se relacionan con el contenido curricular de las materias, haciendo que el aprendizaje tenga significado para el estudiante (Tapia, 2007).

El ApS tiene un componente creativo (Cabrera-Cuevas, 2018) que logra que el estudiante sienta una necesidad en el entorno cercano que le afecta (lo cual genera empatía) y sobre la que reflexiona, imaginando que puede actuar para cambiarla. Este proceso le lleva a la acción, reforzando su confianza y, una vez que ha decidido actuar (prestar un servicio a la comunidad), procede a evaluar el resultado de su actuación, contribuyendo al desarrollo de su pensamiento crítico. Finalmente, comparte los resultados de la experiencia con los demás para saber cómo mejorarla y tratar de implementarla en otros ámbitos. Este planteamiento encaja con la metodología Design for Change, caracterizada por la concurrencia en su diseño de cinco pasos fundamentales: sentir, imaginar, actuar, evaluar y compartir.

El presente Proyecto de Aprendizaje-Servicio se ha implementado por el Grupo de Innovación Docente de la UNED (Seguridad, Control de Fronteras, Migraciones y Derechos Humanos) en colaboración con el Ayuntamiento de Madrid durante el curso 2019-20.

El servicio inherente al ApS prestado a la comunidad ha consistido en la propuesta de indicadores para evaluar la eficiencia del Plan Operativo contra la Trata y otros Abusos de Derechos Humanos en contextos de prostitución, implementado por el Ayuntamiento de Madrid en el período 2018-20. De este modo, se ha logrado:

- Cubrir una necesidad social para mejorar la eficiencia en la utilización de los recursos públicos adscritos al Plan Operativo señalado.

- Poner a disposición del Consistorio de Madrid herramientas para favorecer la transparencia y la rendición de cuentas de su gestión ante la ciudadanía y contribuir a mejorar la legitimación de su acción de gobierno ante los ciudadanos.

- Dar contenido al Convenio ${ }^{3}$ que tiene suscrito desde 2017 el Ayuntamiento con las Universidades de Madrid y la UNED para la puesta en marcha de Proyectos de ApS en la ciudad de Madrid.

${ }^{3}$ Acuerdo recogido en la Resolución de 11 de septiembre de 2017, de la Secretaría General Técnica. 
La dimensión de aprendizaje del Proyecto ha tenido tres objetivos fundamentales:

- Completar la formación de los alumnos que se han implicado en su desarrollo en lo relativo a la elaboración de indicadores para la evaluación de programas sociales, en este caso, del Plan Operativo...

- Acercarles al análisis del contenido y la implementación de un programa social.

- Mejorar su sensibilización en relación a los ODS: 4, 10, 11, 12 y 16 vinculados al Proyecto.

El resultado principal del Proyecto ha sido la propuesta de 48 indicadores para evaluar el mencionado Plan y otros de carácter cualitativo que afectan a todos los agentes involucrados.

\section{Marco teórico ${ }^{4}$}

La implantación del denominado modelo de Bolonia en la enseñanza superior ha comportado la necesidad de que la Universidad proporcione competencias intelectuales o participativas, genéricas, específicas, profesionales o de investigación a sus estudiantes y adapte su modelo tradicional de formación a este nuevo enfoque (González-Rabanal y Martínez-Quintana, 2020).

Esta vinculación de los estudios universitarios a la adquisición de competencias ha sido un elemento especialmente facilitador para el éxito del ApS por su potencial para catalizar la acción política y social y formar en conocimientos y en sensibilidad ciudadana a los estudiantes (Martínez-Lozano, Rodríguez, Marco y Macías, 2020).

La esencia del ApS reside en prestar un servicio a la comunidad, contribuyendo a mejorar la formación personal (Puig, Batlle, Bosch y Palos, 2007), compartiendo con otras herramientas como el Aprendizaje basado en problemas, el voluntariado, los programas de prácticas o la educación de campo, la teorización práctica y el aprendizaje en situación (García, 2011). No obstante, el servicio que integra el $\mathrm{ApS}$ es diferente porque, además de incorporarse al currículum de los estudiantes, surge de la deliberación y el compromiso (Mayor, 2020), se orienta a la adquisición

\footnotetext{
${ }^{4}$ Una exposición más amplia de lo que el ApS representa en el ámbito del aprendizaje experiencial y lo que la doctrina opina del mismo puede consultarse en González-Rabanal (2021), especialmente en las páginas 19-64.
} 
de competencias cívicas y permite tomar conciencia de los aspectos relevantes de la realidad social, irradiando su utilidad sobre todos los actores implicados.

También es diferente del de otras formas de aprendizaje experiencial ya sea narrado, como el estudio de caso (Jameson, Masterman y Walker, 2009) o el Aprendizaje Basado en Problemas (Taplin, 2000), o vivencial, como ocurre con el trabajo de campo, el voluntariado o las prácticas, porque el ApS comporta una auténtica filosofía educativa (García-Gutiérrez, Ruiz-Corbella y del Pozo 2020), que va más allá de la idea de caridad y vincula el conocimiento de los estudiantes a la solución de problemas reales que preocupan a la sociedad y a los ciudadanos. También porque mezcla la teoría con la práctica de una forma especial y consigue dar sentido al aprendizaje al contextualizarlo y referirlo a situaciones reales, otorgando calidad al servicio solidario (Batlle y Escoda, 2019).

Furco (2004), al comentar los efectos del ApS, enfatiza sus distintos elementos de carácter académico y cognitivos y alude a su dimensión de formación cívica, a los aspectos vocacionales y profesionales, éticos y morales, personales y sociales, por lo que su espectro de aplicación es enorme, tanto en el aprendizaje formal como informal, en cualquier nivel educativo y a lo largo de toda la vida del estudiante, así como en ámbitos del conocimiento tan diversos como el Derecho (Morin y Waysdorf 2011), la Ciencia Política (Seider, Susan y Rabinowicz, 2012), la Salud Pública (Suzanne, Cashman, DaSarena y Seifer, 2008) o la Tecnología (Salam, Awang Iskandar, Ibrahim y Farooq, 2019).

El ApS otorga un gran protagonismo a la reflexión y a la formación en valores, transformando a los estudiantes en ciudadanos activos y responsables (Batlle y Escoda), dispuestos a cumplir sus deberes y a profundizar en el conocimiento de la extensión de sus derechos y a contribuir con sus acciones al logro del bien común, preparándolos mejor para ejercer la ciudadanía y perfeccionar la sociedad (Mendía, 2008).

Desde el punto de vista cualitativo, el ApS opera cambios sustanciales en el rol de los propios docentes y erige a la Universidad en un auténtico agente de cambio con sensibilidad ciudadana (Martínez-Lozano, Rodríguez, Marco y Macías, 2020), transformado el proceso de enseñanza-aprendizaje (Francisco y Moliner, 2010), generando resultados educativos difícilmente alcanzables con otras herramientas (Puig et al., 2007) y mejorando el compromiso académico de los estudiantes (Rodríguez-lzquierdo, 2020).

En el caso de la enseñanza online puede llegar a integrar los contenidos teóricos de las Fuentes Educativas en Abierto (OER) con la práctica, dando lugar a lo que Karunanayaka, Naidu y Rajendra (2015) han denominado Prácticas Educativas 
en Abierto (OEP), expandiendo los propios límites de este modelo educativo no presencial (Roberts, Kigotho y Stagg, 2018).

Por su parte, el uso de indicadores es esencial para la evaluación de los programas públicos. La evaluación es un análisis crítico del funcionamiento de un programa a partir de la medición de forma sistemática y continua en el tiempo de sus resultados e impacto teniendo en cuenta sus objetivos y metas, que compara con los deseados o planeados (Ministerio de Mujer y Desarrollo Social de Perú, 2007) para mejorar los estándares de desempeño de la propia institución (Armijo y Bonnefoy, 2005)

Se define a través de los conceptos de: gestión pública, control y democracia (Guía de Evaluación de políticas públicas del Gobierno Vascol y permite determinar la pertinencia y el logro de los objetivos, la eficacia, la eficiencia, el impacto y la sostenibilidad del programa al que se aplica (OCDE, 2002), ofreciendo muchos enfoques y modalidades en función de quién la realice, cuándo, cómo y para qué (Picado, 1987).

Su auge viene explicado por la reformulación de la relación entre los poderes públicos y la sociedad civil, que ha concedido mayor importancia a los resultados de su actuación que a los insumos y procesos (Kliksberg y Ribera, 2007).

Una evaluación adecuada proporciona unos resultados creíbles, fiables y robustos (Asenjo, 2016) que contribuyen a mejorar la transparencia para la rendición de cuentas, es decir, demostrar el cumplimiento de los fines sociales con los que está comprometida la institución (Martín y Richard, 2003).

En el Proyecto se ha orientado la evaluación hacia la eficacia, para conocer el grado de cumplimiento del objetivo del Plan, y la calidad, para medir los atributos, las características de los bienes y servicios que oferta (CONEVAL, 2013) y permitir conocer la cobertura y/o la focalización del servicio prestado a la población objetivo (Departamento Administrativo de Función Pública, 2012). La identificación de los impactos del Proyecto, al tener un planteamiento epistemológico, obliga a considerar también las percepciones de los sujetos participantes (Arancibia, De la Vega, Denis y Saball, 2015).

El proceso evaluativo requiere de la recopilación de datos mediante la elaboración de indicadores, es decir, de expresiones cuantitativas o cualitativas observables de características, comportamientos o fenómenos descritos por la evolución de una variable o la relación entre varias con unos propósitos específicos de planificación para ayudar al diseño y la asignación de los recursos públicos, a la rendición de 
cuentas, a conocer cómo se llevan a cabo los servicios prestados para elevar su calidad, rendimiento y eficacia, posibilitando la retroalimentación o mejora de los proyectos (Niño Martínez-Castro y Macorra, 2013).

Los indicadores deben ser específicos, explícitos, claros, confiables, exactos, económicos, monitoreables, adecuados, relevantes (CONEVAL, 2013), oportunos, no redundantes, sensibles, simples, transparentes y verificables (Tribunal Supremo de Elecciones de Costa Rica, 2017), factibles y tener continuidad (Mondragón, 2002) y su construcción requiere conocer el marco legal que determina las necesidades de información para medir la situación del programa respecto a determinados valores o metas perseguidas y asociarse al logro de la misión y de los fines institucionales o del propio programa (Martín y Richard, 2003).

Además, deben enmarcarse en un análisis teórico previo, pudiendo presentar diferentes modalidades: absolutos, relativos, objetivos, subjetivos, simples, sintéticos, analíticos o descriptivos (Navarro y Larrubia, 2006).

En términos generales, los indicadores pueden ser de eficacia, de eficiencia, de calidad o de economía Secretaría de Finanzas y Administración (2015) y pueden desarrollarse sobre diferentes ámbitos de desempeño: de resultados, de productos, de procesos o de insumos (CONEVAL, 2013).

Se considera que un indicador es óptimo si dota a quien se encarga del Proyecto de la información necesaria para la toma de decisiones al tiempo que permite a su gestor sentirse seguro y confiado en la medición de sus resultados.

\section{Objetivos del Proyecto}

El objetivo central del Proyecto ha sido llevar a cabo una experiencia de Aprendizaje-Servicio, al amparo del marco jurídico antes comentado, consistente en proponer indicadores para evaluar un Programa de contenido social de los que despliega el Ayuntamiento de Madrid.

Nuestro Proyecto se concretó en la propuesta de indicadores para evaluar el Plan Operativo contra la Trata y otros abusos de Derechos Humanos en contextos de prostitución (2018-20).

Junto a dicho objetivo, la experiencia de APs ha contemplado otros que se recogen en la Tabla 1: 


\section{TABLA I. Objetivos del Proyecto de Aprendizaje-Servicio}

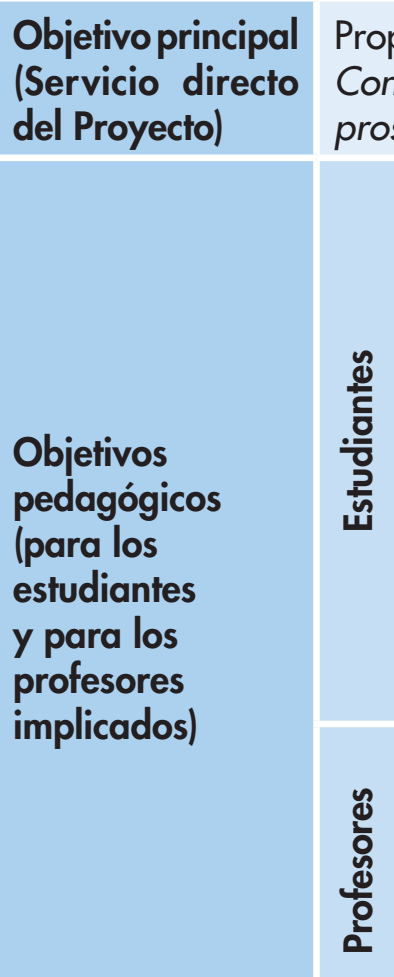

\section{Otros objetivos}

Trabajo colaborativo entre las instituciones implicadas

Otros objetivos

Proponer un conjunto de indicadores para evaluar el Plan Operativo Contra la Trata y otros Abusos de Derechos Humanos en contextos de prostitución, implementado por el Ayuntamiento de Madrid (2018-20).

Completar la formación de los alumnos de las asignaturas de Gestión Pública (del Grado en Ciencias Jurídicas de las Administraciones Públicas) y de Planificación y Evaluación de los Servicios Sociales (del Grado en Trabajo Social) en los términos siguientes:

- Profundización en el conocimiento de cómo se elaboran indicadores para evaluar programas de contenido social como el Plan propuesto.

- Concienciación ante algunos de los problemas sociales que preocupan a la ciudadanía y a las instituciones (la Trata y otros abusos de Derechos Humanos).

- Sensibilización acerca de los $\operatorname{ODS}(4,10,11,12$ y 16) relacionados con el Proyecto.

Enriquecer las herramientas metodológicas empleadas por los docentes en el ámbito de los contenidos de las dos asignaturas comentadas, contemplando una propuesta transdisciplinar (Campo, 2015) que pusiera en valor su formación interdisciplinar y permitiera la elaboración de materiales comunes para la preparación de ambas disciplinas.

Desarrollar el Convenio antes mencionado.

Colaborar con el Ayuntamiento de Madrid para mejorar la eficiencia en la gestión de sus recursos, la transparencia en el ejercicio de su actividad y la rendición de cuentas ante la ciudadanía.

Contribuir a revertir hacia la sociedad los resultados de los recursos empleados por la UNED en la formación de los estudiantes.

Mejorar el compromiso cívico de sus estudiantes en línea con lo previsto en el Estatuto del Estudiante Universitario ${ }^{5}$.

Favorecer su empoderamiento.

Reforzar la visualización social de la actividad formativa de la UNED y contribuir a incrementar su responsabilidad social corporativa (GonzálezRabanal, 2021).

Explorar la posibilidad de aplicar experiencias análogas con otras instituciones y programas sociales.

Nota: Elaboración propia a partir de Puig Rovira, J. M. (2009).

${ }^{5}$ Aprobado por Real Decreto 1791/2010, de 30 de diciembre. 


\section{Metodología y método}

Entendiendo que la metodología ${ }^{6}$ define, clasifica y sistematiza el conjunto de técnicas y sistemas que se utilizan en una investigación científica determinada, se puede señalar que el Proyecto ha seguido una orientación cualitativa y de metasíntesis cualitativa, asociada al proceso de análisis de los datos obtenidos por los estudiantes, su preparación, revisión, transcripción, organización, categorización y análisis, con el fin de ofrecer el Informe con los resultados más relevantes a los responsables del Ayuntamiento de Madrid.

La metasíntesis requiere delimitar el tópico del área de interés del investigador y conocer estudios anteriores (Finfgeld, 2003) y acude a los reportes de otras investigaciones para identificar hallazgos más específicos (Beck, 2001).

Para ello, a los estudiantes se les ha facilitado el documento': Apoyando a las víctimas de trata las necesidades de las mujeres víctimas de trata con fines de explotación sexual desde la perspectiva de las entidades especializadas y profesionales involucrados. Propuesta para la sensibilización contra la trata de la Delegación de Gobierno para la violencia de género de Madrid, para que conocieran mejor las dimensiones y los perfiles de las mujeres que son víctimas de trata y pudieran contextualizar y analizar más adecuadamente el Plan Operativo implementado por el Ayuntamiento de la capital.

Ha combinado también aspectos de la investigación participativa ya que los indicadores se han formulado a partir de las propuestas de los estudiantes implicados en el Proyecto.

\footnotetext{
- Una muy interesante exposición de las metodologías mixtas de análisis es la realizada por E. Halcomb y L. Hickman (2015).

${ }^{7}$ Aun reconociendo que el tratamiento de la Trata admite muchos y plurales enfoques por el carácter multidimensional que puede revestir este problema como puede ser el ámbito de los derechos laborales (véase L. Kiss y C. Zimmerman (2019) y asumiendo la importancia de conocer el detalle de otras propuestas de actuación ante los riesgos que comporta la migración laboral de las mujeres y el posible conflicto con sus derechos (T. Blanchet, H. Biswas, A. Zaman y M.A. Lucky, 2018) y de que resulta muy ilustrativa la consulta de documentos como el "Human Trafficking and Modern Slavery: New insights for Policy and Programmes", o el "New insights for policy and programmes. Emerging findings from Study on Work in Freedom Transnational Evaluation", hemos creído conveniente no sobrecargar a los estudiantes con la lectura de mucho material y centrarnos en este documento de la Delegación de Gobierno de Madrid que puede aportarles una visión general del problema y de su abordaje en un entorno muy cercano.
} 
El análisis de todo el período de implementación del Plan Operativo ha permitido realizar una investigación longitudinal para ver la evolución de las características y variables observadas y determinar las más relevantes al objeto de proponer los indicadores.

El equipo vinculado al Proyecto ha estado integrado por tres profesores de la Facultad de Derecho, una profesora de la Facultad de Ciencias Políticas y Sociología, todos ellos de la UNED, y una profesora del Departamento de Economía y Estadística de la Universidad de León.

Los estudiantes participantes han sido tres alumnos de la asignatura de Gestión Pública, del tercer curso del Grado en Ciencias Jurídicas de las Administraciones Públicas, y dos de Planificación y Evaluación de los Servicios Sociales, del tercer curso del Grado en Trabajo Social, todos de la Facultad de Derecho de la UNED. Ambas materias se imparten en el primer cuatrimestre, lo cual ha facilitado la gestión del Proyecto para que se pudiera realizar de forma simultánea.

Como actividades formativas específicas para la familiarización con el ApS, los profesores han realizado el MOOC: "Iniciación a la puesta en marcha de proyectos de aprendizaje-servicio" y los estudiantes el curso "Proyectos de aprendizaje-servicio en la universidad", ambos disponibles en UNED Abierta, previo registro a través de: iedra.uned.es

Para el desarrollo de los indicadores los alumnos han trabajado los artículos de Donoso, Luna y Velasco (2012); de Sánchez, Martín y Palacios (2015) y de Jara y Romero (2009).

El método (plan) seguido para llevar a cabo el Proyecto de ApS se realizó íntegramente online, a través de la plataforma educativa de la UNED (aLF). Las principales actuaciones llevadas a cabo se detallan a continuación:

- Anuncio del Proyecto en el espacio virtual de la plataforma alF de las dos asignaturas implicadas.

- Anuncio del proceso de selección de los estudiantes para participar en él (envío de una carta de motivación).

- Creación de todas las tareas asociadas a su implementación, en concreto, el envío de la carta de motivación ${ }^{8}$, la prueba para el control de las lecturas anteriormente

\footnotetext{
${ }^{8}$ Este requisito nos permitiría seleccionar a los estudiantes más idóneos en el caso de que las peticiones superaran la cifra de los 10 previstos. Fueron admitidos todos los estudiantes ya que inicialmente se apuntaron 7, aunque solo 5 concluyeron todas las actividades del Proyecto.
} 
indicadas, la entrega de la propuesta de indicadores, el enlace al cuestionario de valoración de la experiencia y el reporte de haberlo cumplimentado.

- Apertura de un foro específico en cada asignatura para responder las dudas de los estudiantes implicados en el Proyecto.

- Creación de un repositorio de documentos en aLF tras el análisis y selección de lecturas complementarias ya mencionadas para que los estudiantes pudieran consultar y trabajar todo el material, además de los documentos sobre el Plan... proporcionados por el Consistorio de la capital.

- Preparación y corrección del cuestionario online de 20 preguntas que realizaron los alumnos sobre el contenido de las mencionadas lecturas, con el correspondiente feedback a sus respuestas.

- Evaluación activa de las propuestas de indicadores de los estudiantes.

- Solicitud al Rectorado de la concesión de 2 créditos ECTS por su participación en el Proyecto y concesión de 0.5 puntos adicionales en la calificación de las asignaturas, al considerar la participación en el Proyecto como una prueba de evaluación continua (PEC) de carácter voluntario.

- Estudio y sistematización en categorías de los indicadores elaborados por los estudiantes, en consonancia con el Plan objeto de estudio.

- Elaboración del Documento de síntesis con la propuesta de indicadores.

- Presentación de los resultados del Proyecto a los responsables del Ayuntamiento de Madrid involucrados en su desarrollo, en las reuniones mantenidas con ellos el 27 de febrero y el 10 de marzo de 2020.

- Diseño de un cuestionario de valoración de la experiencia e implementación del mismo a través de Google Forms ${ }^{9}$. Dicho cuestionario abarca las dimensiones siguientes: identificación genérica del estudiante mediante su email, titulación y asignatura, perfil (sexo, edad, nacionalidad, situación laboral, estado civil, nivel de estudios), motivación para realizar el Grado (conocimiento de su existencia, motivos para cursarlo), motivación para participar en el ApS, opinión sobre el proceso de selección, sobre las tareas y actividades, sobre el apoyo del equipo docente, atractivo de Universidad y de la enseñanza online, estructura y contenido del Proyecto de ApS, valoración de la experiencia.

${ }^{9}$ Los alumnos accedían al cuestionario a través del siguiente enlace: https://forms.gle/ KQUpgZAmAHTyDnDp9 
- Análisis de las respuestas de los alumnos al cuestionario para poder identificar los puntos débiles y fuertes de la experiencia e incorporar las mejoras necesarias del Proyecto en futuras convocatorias.

- Valoración de los resultados del Proyecto entre los miembros del equipo docente y su difusión en diferentes medios.

- Presentación del Proyecto a la convocatoria 2020 de Premios UNED-Banco Santander de Investigación, Transferencia del conocimiento y Divulgación 2020 en la modalidad de transferencia.

- Elaboración de la Memoria final para presentarla al Instituto Universitario de Educación a Distancia (IUED), responsable de la convocatoria de los proyectos de innovación docente al amparo de la cual se ha realizado el ApS.

- Diseño y realización de una serie de programas de radio (Radio3) ${ }^{10} \mathrm{con}$ la participación de los profesores y un estudiante para comentar y difundir los resultados de la experiencia.

\section{Resultados del Proyecto}

Los resultados del Proyecto han sido tanto cuantitativos como cualitativos. Los cuantitativos (valor numérico) se han formalizado en la propuesta de 48 indicadores para evaluar diferentes aspectos del Plan, aunque algunos tienen carácter cualitativo como los que se refieren al grado de implicación de los estudiantes y a su valoración.

Con carácter general, los resultados cualitativos se refieren a mejoras en la forma de concebir la docencia universitaria para todas las instituciones y colectivos implicados: los docentes, los estudiantes, el Ayuntamiento de Madrid y la propia UNED.

\section{I. Resultados cuantitativos}

Los 48 indicadores propuestos se han agrupado en dos bloques. El primero de ellos se refiere a los indicadores para evaluar el Plan Operativo y está integrado por las cuatro categorías que dan contenido a la Tabla 2.

${ }^{10} \mathrm{~A}$ los que se puede acceder a través del siguiente enlace: https://canal.uned.es/ series $/ 5 \mathrm{fc} 77 \mathrm{e} 4 \mathrm{bb} 6092332 \mathrm{fb} 747 \mathrm{f} 17$ 
Dichos indicadores recogen las propuestas formuladas por los estudiantes participantes en el Proyecto de forma consolidada y ordenada para una más adecuada presentación formal. Como se puede observar, en unos casos se trata de indicadores cuantitativos y en otros cualitativos.

\section{TABLA 2. Propuesta de indicadores para evaluar el Plan Operativo contra la Trata y otros abusos de Derechos Humanos en contextos de prostitución}

\section{Indicadores relacionados con la investigación y mejora del conocimiento (6)}

Número de productos generados por el grupo de trabajo sobre la trata de mujeres y otros abusos de derechos humanos.

Número de reuniones mantenidas con el grupo de trabajo.

Número y relación de demandas y necesidades evaluadas.

Número y relación de personas expertas y entidades sociales especializadas participantes en el desarrollo del Plan.

Número de los recursos específicos destinados a la atención integral frente a la trata de mujeres y otros abusos en contextos de prostitución.

Número de recomendaciones recogidas al finalizar la implementación del Plan sobre los recursos específicos destinados a la atención integral frente a la trata de mujeres y otros abusos en contextos de prostitución.

\section{Indicadores relacionados con la Educación y la concienciación social sobre la temática del Plan (6)}

Número de colaboraciones llevadas a cabo para el desarrollo del Plan.

Número de actividades de concienciación realizadas.

Número de personas participantes en las actividades y categorización (jóvenes, mujeres, hombres).

Creación de una comunidad educativa online.

Número y cuantía de las subvenciones concedidas por el Ayuntamiento para desarrollar actuaciones de educación afectivo-sexual en el ámbito educativo formal y no formal.

Incorporación de organizaciones de hombres frente a la violencia machista en la implementación de acciones de concienciación. 


\section{Indicadores relacionados con la detección del problema y la coordinación de las actuaciones (11)}

Número de acciones formativas específicas dirigidas a profesionales.

Número de profesionales participantes en las actividades.

Número de protocolos de detección y derivación de casos elaborados.

Evolución anual de la detección de casos de trata y vulneración de derechos.

Cuantía y evolución anual de los recursos de la Red de Atención Integral que cuentan con un agente mediador.

Existencia de un protocolo de derivación de víctimas de trata menores de edad.

Número de reuniones de la mesa técnica de trata.

Creación de sistemas de coordinación intra-municipal.

Número de propuestas de mejora en la detección, atención y coordinación intra-municipal elevadas en relación al total de las identificadas.

Existencia de espacios de trabajo y coordinación desarrollados con otras instituciones.

Número de sesiones de trabajo y formación conjunta realizadas con la Policía Nacional, Fiscalía y Judicatura.

\section{Indicadores relacionados con la atención integral y la reparación a las víctimas (17)}

Existencia de un Informe que contemple aspectos como: los obstáculos al empadronamiento de estas mujeres y si se ha trasladado al Grupo de trabajo sobre empadronamiento y sectores vulnerables del Ayuntamiento de Madrid.

Porcentaje de propuestas de mejora elevadas al Grupo de trabajo.

Creación de un Centro de emergencia municipal para mujeres víctimas de trata y otros abusos de derechos humanos en contextos de prostitución que cuente con un teléfono de atención 24 horas.

Número de mujeres víctimas de trata atendidas en el centro de emergencia municipal.

Número de beneficiarias del alojamiento semiautónomo, desagregado por mujeres y menores a cargo.

Porcentaje y evolución del número de mujeres alojadas en el centro de acogida.

Porcentaje de las recomendaciones recogidas en la evaluación realizada puestas en marcha en relación al total de las mismas.

Número de beneficiarias de acciones de acompañamiento judicial atendidas por los recursos municipales de la Red de Atención Integral.

Existencia de materiales informativos en distintos idiomas para el acceso a los servicios del Plan.

Existencia de un modelo de intervención sociolaboral de los recursos municipales. 
Porcentaje de las conclusiones recogidas en el Proyecto Building Choices para intervención sociolaboral puestas en marcha con los recursos municipales sobre el total de las recogidas en el mismo.

Incremento de itinerarios de capacitación para el empleo en sectores que no están mayoritariamente feminizados y precarizados realizados sobre el total de itinerarios llevado a cabo.

Incremento de las acciones de acompañamiento para la inserción laboral.

Número de acciones de impulso del autoempleo y emprendimiento implementadas con los recursos de la Red Municipal de Atención Integral.

Número de empresas colaboradoras en la inserción laboral de estas mujeres en relación con el total de empresas contactadas.

Incorporación de menciones de la realidad histórica de mujeres en contextos de prostitución durante la vigencia del Plan.

Número de actuaciones de reconocimiento social y memoria de víctimas de la trata con fines de explotación sexual y otros abusos de derechos humanos en contextos de prostitución.

Nota: Elaboración propia a partir de los resultados del Proyecto.

El segundo bloque está formado por los 8 indicadores de impacto en el aprendizaje y de impacto social del Proyecto con el fin de poder determinar el éxito de la herramienta de ApS, que se recogen en la Tabla 3.

\section{TABLA 3. Indicadores de impacto en el Aprendizaje y de impacto social del Proyecto de Aprendizaje-Servicio}

\section{Indicadores de impacto en el aprendizaje (4)}

Número de alumnos interesados en participar en el Proyecto.

Grado de implicación de los alumnos participantes.

Valoración por parte de los alumnos de todas las tareas propuestas.

Existencia de un Informe final para evaluar el éxito del Proyecto y la formulación de posibles líneas de mejora.

\section{Indicadores de impacto social (4)}

Aplicación de los indicadores obtenidos a otros Programas del Ayuntamiento de Madrid.

Evaluación por parte del Ayuntamiento de Madrid del grado de eficiencia alcanzado en el Proyecto en la evaluación del Programa seleccionado.

Publicación de los principales resultados del Proyecto.

Existencia de un Informe final para evaluar el éxito del Proyecto y sugerencias de futuras líneas de mejora.

Nota: Elaboración propia a partir de los resultados del Proyecto. 


\subsection{Resultados cualitativos}

Los estudiantes implicados han podido completar la formación sobre indicadores con el material ad hocy la experiencia práctica, por lo que el Proyecto ha alcanzado su objetivo educativo principal que ha enriquecido con otros resultados de carácter cualitativo que afectan a todos los actores implicados y que se sintetizan en la Tabla 4:

\section{TABLA 4. Resultados cualitativos derivados del Proyecto}

\begin{tabular}{|c|c|}
\hline \multirow{5}{*}{$\begin{array}{l}\text { Para los } \\
\text { docentes }\end{array}$} & $\begin{array}{l}\text { Establecimiento de un espacio interdisciplinar e interfacultativo fruto del } \\
\text { planteamiento transversal de la experiencia (Trabajo Social y Ciencias } \\
\text { Jurídicas de las Administraciones Públicas) y de la formación diversa de } \\
\text { los integrantes del equipo docente (Trabajo Social, Derecho, Ciencias } \\
\text { Económicas, Ciencias Políticas y Sociología). }\end{array}$ \\
\hline & $\begin{array}{l}\text { Familiarización con nuevas herramientas de aprendizaje colaborativo, } \\
\text { facilitador de la adquisición de competencias para los estudiantes. }\end{array}$ \\
\hline & $\begin{array}{l}\text { Innovación metodológica de la docencia de las asignaturas de Gestión } \\
\text { Pública y Planificación y Evaluación de los Servicios Sociales. }\end{array}$ \\
\hline & $\begin{array}{l}\text { Creación de sinergiasentre materias que no estaban conectadas, dandolugar } \\
\text { a un proceso de coordinación, en palabras de Francisco y Moliner (2010). }\end{array}$ \\
\hline & $\begin{array}{l}\text { Ampliación de su horizonte de aprendizaje personal para la búsqueda } \\
\text { de planteamientos más integrales de la formación transversal de los } \\
\text { estudiantes. }\end{array}$ \\
\hline \multirow{4}{*}{$\begin{array}{l}\text { Para los } \\
\text { estudiantes }\end{array}$} & $\begin{array}{l}\text { Superación de la brecha entre teoría y práctica para la elaboración y } \\
\text { aplicación de los indicadores sociales, propiciando una nueva forma } \\
\text { de intersección entre ambas que se podría añadir a las ya señaladas } \\
\text { para la enseñanza blended (presencial y online) por Lukenchuk (2016). }\end{array}$ \\
\hline & $\begin{array}{l}\text { Conocimiento de primera mano del desarrollo del Plan objeto de aná- } \\
\text { lisis, saber cómo se articula, cuáles son sus objetivos y prioridades, } \\
\text { acercarmiento a una realidad en la que desarrollarán el ejercicio de su } \\
\text { profesión y familiarización con su entorno con la finalidad de mejorarlo. }\end{array}$ \\
\hline & $\begin{array}{l}\text { Incremento de su empoderamiento personal mostrándoles cómo, con } \\
\text { sus aportaciones, pueden contribuir a mejorar el empleo de los recursos } \\
\text { públicos, es decir, incidiendo en su motivación general para el estudio, } \\
\text { aumentando su autoestima y sus expectativas personales. }\end{array}$ \\
\hline & $\begin{array}{l}\text { Refuerzo de su educación en valores (Puigy Palos, 2006), al sensibilizarlos } \\
\text { sobre las situaciones de marginalidad y exclusión social contempladas } \\
\text { en el Plan... }\end{array}$ \\
\hline
\end{tabular}




\begin{tabular}{|c|c|}
\hline \multirow[t]{2}{*}{$\begin{array}{l}\text { Para los } \\
\text { estudiantes }\end{array}$} & $\begin{array}{l}\text { Profundización en el conocimiento y en la praxis de parte de los conteni- } \\
\text { dos curriculares (indicadores) al desarrollar competencias transversales } \\
\text { que difícilmente podrían adquirir en las aulas (Folgueiras, Luna y Puig, } \\
2013 \text { ) y que los predisponen mejor para la resolución de problemas y } \\
\text { para enfrentarse más adecuadamente a los retos profesionales cuando } \\
\text { finalicen sus estudios en la UNED. }\end{array}$ \\
\hline & $\begin{array}{l}\text { Conocimiento de medidas para abordar problemas sociales conectados } \\
\text { con los ODS: } 4,10,11,12 \text { y 16, mediante la implementación del Plan... } \\
\text { objeto de análisis. }\end{array}$ \\
\hline \multirow{3}{*}{$\begin{array}{l}\text { Para el } \\
\text { Ayuntamiento } \\
\text { de Madrid }\end{array}$} & $\begin{array}{l}\text { Suministro de indicadores para evaluar la eficiencia del Plan Operativo } \\
\text { Contra la Trata y otros Abusos de Derechos Humanos en contextos de } \\
\text { prostitución (2018-20). }\end{array}$ \\
\hline & $\begin{array}{l}\text { Contribución a la transparencia de su gestión y a la rendición de cuentas } \\
\text { a los administrados, que son objetivos de la acción de gobierno de las } \\
\text { instituciones públicas. }\end{array}$ \\
\hline & $\begin{array}{l}\text { Aproximación al conocimiento que se imparte en la Universidad y posi- } \\
\text { bilidad de saber de su utilidad para el funcionamiento de las instituciones } \\
\text { y para el empleo eficiente de los recursos públicos. }\end{array}$ \\
\hline \multirow{6}{*}{ Para la UNED } & $\begin{array}{l}\text { Favorece la transferencia de su actividad hacia la sociedad mediante la } \\
\text { presentación de los resultados del Proyecto ante los responsables de la } \\
\text { Oficina de Proyectos APS del Ayuntamiento de Madrid ( } 27 \text { de febrero } \\
\text { de } 2020 \text { ) y de la Dirección General de Innovación y Estrategia Social } \\
\text { (10 de marzo de 2020) y en otros foros y publicaciones. }\end{array}$ \\
\hline & $\begin{array}{l}\text { Da contenido al Convenio de colaboración que tiene suscrito con el } \\
\text { Ayuntamiento de Madrid de } 2017 \text {. }\end{array}$ \\
\hline & Mejora su responsabilidad social corporativa (Campo, 2015). \\
\hline & $\begin{array}{l}\text { Estrecha su colaboración con el Ayuntamiento, secundando su compromiso } \\
\text { de ayudar a la creación de una ciudad educadora (Puig y Palos, 2006). }\end{array}$ \\
\hline & $\begin{array}{l}\text { Contribuye a la institucionalización de este tipo de experiencias en sus } \\
\text { enseñanzas, al permitir la replicación de los proyectos exitosos. }\end{array}$ \\
\hline & $\begin{array}{l}\text { Mejora su imagen entre los estudiantes al potenciar el impacto y la } \\
\text { proyección social del Proyecto }{ }^{11} \text {. }\end{array}$ \\
\hline
\end{tabular}

Nota: Elaboración propia.

\footnotetext{
${ }^{11}$ Todos los estudiantes que participaron en el Proyecto recibieron un certificado de reconocimiento personalizado expedido por el Director General de Innovación y Estrategia Social.
} 


\section{Discusión}

Una de las novedades del Proyecto ha sido la adaptación de la metodología específica del ApS a la enseñanza online de la UNED y a su plataforma educativa aLF. Que sepamos, es la primera vez que se diseña un proyecto de ApS en el que la prestación del servicio a la comunidad no requiere la presencia física en la entidad receptora, es decir, que ha sido concebido para desarrollarse totalmente online.

Hemos comprobado que el empleo de herramientas online es una ventaja porque permite incorporar al Proyecto a cualquier estudiante. Así, la experiencia tiene una dimensión global y plural. Esta capacidad para vincular a alumnos de cualquier lugar es especialmente relevante en un momento como el actual en el que los contactos físicos están restringidos para luchar frente al Covid-19.

Otra de las fortalezas del Proyecto ha sido la composición interdisciplinar del equipo docente que favorece la transversalidad del conocimiento y crea sinergias entre los conocimientos de las dos asignaturas implicadas en su desarrollo (al aprovechar que comparten contenidos comunes) fortalecidas por la formación complementaria de los docentes implicados. Además, la diferente procedencia y orientación profesional de los estudiantes (el Trabajo Social y las Ciencias Jurídicas de las Administraciones Públicas) permite conocer un espectro mayor de aportaciones.

Experiencias como la realizada favorecen la institucionalización del ApS en el entorno universitario y ello por dos razones. La primera, por la buena acogida que ha tenido entre los estudiantes involucrados en el Proyecto los cuales, en su totalidad, la han valorado como una experiencia positiva en general, indicando que todas las asignaturas deberían ofrecer la posibilidad de realizar una parte práctica puesto que ayuda al alumno a acercarse al trabajo de campo ${ }^{12}$, completar los elementos de enganche de los estudiantes a la enseñanza online y ampliar los señalados por Delahunty, O'Shea y Stone (2015). Prueba de ello es el éxito de la nueva propuesta para el presente curso 2020-21 en la que han participado 17 estudiantes. La segunda, porque ha conseguido involucrar a un equipo de profesores de formación interdisciplinar que la están llevado a cabo en diferentes asignaturas y Grados, cuyo trabajo ha sido reconocido con el Premio UNED-Banco Santander 2020 de Investigación, Transferencia y Divulgación Científica en su modalidad de transferencia ${ }^{13}$.

${ }^{12}$ Véanse los resultados del cuestionario de satisfacción que se incorpora al final del trabajo como anexo.

${ }^{13}$ Boletín Interno de Coordinación Informativa (BICl) de la UNED n 40 de 27 de julio de 2020 (p. 7). 
Por otro lado, creemos que el atractivo de los programas de contenido social ha favorecido la búsqueda de uno que fuera adecuado para materializar el compromiso entre el Consistorio de Madrid y la UNED para el desarrollo del Aprendizaje-Servicio y para conectar el Proyecto con la sensibilización de los estudiantes con los ODS: $4,10,11,12$ y 16.

Estimamos que el ApS ha mejorado la formación convencional de los estudiantes porque los ha facultado para completar y profundizar en temas que integran el contenido de las asignaturas implicadas (indicadores, evaluación de programas, ODS), los ha conectado con problemas reales, los ha adiestrado en aspectos relacionados con su práctica profesional y los ha empoderado al mostrarles cómo, con sus aportaciones, pueden contribuir a perfeccionar la realidad social.

Finalmente, entendemos que el hecho de que un elemento importante del ApS sea precisamente la prestación de un servicio a la comunidad permite a los responsables de la institución colaboradora disponer de forma gratuita de herramientas para conocer mejor la eficiencia de sus actuaciones y contribuye a dotar de transparencia a su gestión. Ambos aspectos inciden favorablemente en su rendición de cuentas ante la ciudadanía, en la legitimación social de sus actuaciones y permiten la replicación del proyecto en otros ámbitos y con otras instituciones.

\section{Limitaciones y orientación futura}

\section{I. Limitaciones}

Para la implementación del Proyecto se han tenido que soslayar algunas de las dificultades inherentes al modelo de universidad no presencial (Rumble, 2007 y Todhunter, 2013) que añaden cierta complejidad para seleccionar adecuadamente a los alumnos y animarlos para que participen.

Otra limitación es el diseño del servicio para la institución implicada sin desplazamientos físicos a la misma, porque los estudiantes pueden proceder de cualquier lugar de nuestra geografía o del extranjero.

Por otro lado, la elección de las dos asignaturas ha tenido varios condicionantes:

Disponible en: https://www2.uned.es/bici/Curso2019-2020/200727/bici40completo.pdf 
a) Que los docentes participantes en el Proyecto fueran sus coordinadores para conseguir su adecuada implementación al gozar de autonomía a la hora de programar las pruebas de evaluación continua (PEC) vinculadas al desarrollo de la experiencia.

b) Que ambas se impartieran en el mismo cuatrimestre, en este caso en el primero, para poder desarrollar la experiencia de forma simultánea.

c) Que sus programas tuvieran contenidos comunes.

d) Que las materias estudiadas estuvieran conectadas con los ODS y con el ámbito competencial del Ayuntamiento de Madrid.

Pese a todo lo anterior, la principal debilidad del Proyecto, tal y como señalan los estudiantes en el cuestionario de valoración, ha sido el retraso de su puesta en marcha debido a problemas burocráticos que han afectado tanto a la Universidad como al Ayuntamiento de Madrid.

\subsection{Orientación futura}

La orientación futura de este tipo de experiencias pasa por el aprovechamiento de sus indudables ventajas frente a otras formas de aprendizaje experiencial y colaborativo y de su gran capacidad para formar en competencias a los estudiantes en consonancia con las exigencias del modelo de Bolonia y con el compromiso de la Universidad para contribuir a la formación en valores de sus estudiantes y para transferir hacia la sociedad el conocimiento que imparte.

Su propósito último debe ser alcanzar la institucionalización del ApS en el entorno de la Educación Superior, para lo que es necesario potenciar los elementos de apoyo al Aprendizaje-Servicio en el seno de la Universidad. Ello requiere, además de recursos económicos y de la superación de trabas administrativas, del concurso de diferentes voluntades: la de sus equipos de gestión $y$, sin duda, la de los docentes que, como se ha señalado, deben tener grandes dosis de entrega y optimismo para enrolarse en este tipo de experiencias de forma altruista.

Para que dicha institucionalización sea una realidad se requiere un adiestramiento adecuado con el uso del ApS y la dedicación necesaria para la correcta elaboración del proyecto. Además, se precisa de reconocimiento por parte de las instituciones y de la comunidad universitaria por haber asumido este reto de innovar en el ámbito 
del conocimiento, incidiendo en todos aquellos elementos que estimulen el grado de motivación de los implicados, ya sean de índole pecuniaria (disponiendo de recursos para poder realizar otros proyectos de ApS), o de mero valor académico (ECTS, premios a la innovación...).

Es importante aprovechar las oportunidades que en estos momentos brinda el entorno. Por un lado, el marco diseñado por el modelo educativo de Bolonia y la sensibilización social hacia el logro de los ODS; por otro, la preocupación de la Universidad por retornar hacia la sociedad los recursos empleados en la formación de sus estudiantes y, finalmente, la necesidad de las instituciones públicas de dotar de transparencia a sus actuaciones y rendir cuentas del uso de sus recursos ante la ciudadanía.

En nuestra opinión, la configuración del posible futuro escenario del desarrollo generalizado de propuestas de ApS en el entorno de la Educación Superior precisa de un estudio previo y profundo de las demandas y necesidades concretas de las posibles instituciones con las que aliarse para que la prestación del servicio se vincule a la solución de algunos de los problemas que aquejan a nuestra sociedad y, al tiempo, permita dotar a los estudiantes de habilidades y competencias que necesitarán cuando abandonen las aulas de modo que puedan desarrollar de forma crítica y eficiente su actividad profesional.

Finalmente, en lo que se refiere a la posible continuidad del Proyecto, en el actual curso académico 2020-21 seguimos contando con el interés de los responsables de la Dirección General de Innovación y Estrategia Social del Consistorio de Madrid para implementar uno nuevo consistente en proponer indicadores para evaluar los Puntos de Encuentro Familiar (PEF) desarrollados por el Ayuntamiento.

Esto va a permitir adicionalmente que la UNED se visualice como un auténtico agente de cambio social comprometido con la solución de los problemas especialmente sensibles para la ciudadanía.

\section{Conclusiones}

Como valoración global de la experiencia se pueden establecer las siguientes conclusiones:

1. La implementación de experiencias innovadoras como ésta ha puesto de manifiesto que es posible desarrollar proyectos de ApS en universidades con 
enseñanza no presencial, lo cual es especialmente interesante en un momento como el actual en el que los contactos físicos y la movilidad están restringidos.

2. La enseñanza online reviste una gran fortaleza al permitir vincular a estos proyectos a estudiantes de procedencia global, siendo suficiente que dispongan de una conexión a internet, con independencia del lugar en que se encuentren ubicados.

3. Experiencias como la presentada contribuyen a la institucionalización del ApS en el seno de la Universidad desde diferentes puntos de vista: en primer lugar, ampliando las posibilidades de firmar convenios de colaboración con instituciones de muy diversa naturaleza tanto públicas como privadas $y$, en segundo lugar, difundiendo entre los estudiantes la potencialidad de esta herramienta de aprendizaje que contribuye a profundizar en algunos aspectos formativos de su currículum y a conectarlo con una dimensión práctica en la que se involucran formando parte no de una experiencia narrada, sino vivida.

4. Los proyectos de contenido social despiertan en la población, en general, y en los estudiantes, en particular, una especial sensibilidad, por lo que resulta relativamente sencillo involucrarlos en estas iniciativas. Además, es frecuente que los Ayuntamientos y otras instituciones lleven a cabo acciones de carácter social que favorecen su colaboración con la Universidad ya que se conectan con el contenido de muchas de sus asignaturas y permiten la vinculación de sus proyectos con el diseño de experiencias relacionadas con los ODS.

5. Los programas públicos dirigidos a resolver cuestiones que afectan a colectivos marginados refuerzan, además, la formación en valores de los estudiantes y su compromiso cívico, creando en ellos una cierta conciencia ética que les permitirá sentir, juzgar, deliberar (argumentar) y actuar conforme a valores morales de modo coherente, persistente y autónomo, sabiendo en cada momento cuál es la forma correcta de proceder ante cualquier situación que se les presente, en cualquier ámbito de sus vidas.

6. La implementación de proyectos análogos al presentado colabora en la misión de la Universidad de transferir hacia la sociedad el conocimiento que en ella se desarrolla, mejora su imagen social y coadyuva a potenciar su responsabilidad corporativa. De este modo, la Universidad se erige en una educadora para la ciudadanía global. 
7. El diseño de experiencias de carácter interdisciplinar favorece la creación de sinergias entre los contenidos de las asignaturas implicadas y ha puesto de manifiesto que es posible (y conveniente) articular mecanismos de transversalidad que refuercen los aprendizajes de las asignaturas para multiplicar los resultados de sus avances pedagógicos, innovadores e investigadores.

8. El Proyecto ha contribuido a mejorar la formación de los estudiantes en temas que integran el contenido de las asignaturas implicadas (indicadores, evaluación de programas, ODS), les ha conectado con problemas reales, les ha adiestrado en aspectos relacionados con su práctica profesional y les ha empoderado al mostrarles cómo, con sus aportaciones, pueden contribuir a mejorar la realidad social.

9. El servicio prestado al Ayuntamiento de Madrid beneficia a los responsables de implementar el Plan... al poder conocer mejor su eficiencia y aportar transparencia y legitimación social a sus actuaciones.

10. El diseño de este Proyecto tiene una gran versatilidad para poderse replicar con éxito en otros programas o en colaboración con otras instituciones.

11. Esta experiencia de ApS ha permitido a los docentes implicados en su desarrollo tomar conciencia de la importancia de colaborar en el desarrollo de competencias transversales de formación para los estudiantes y de las ventajas derivadas de su propia formación interdisciplinar, posibilitando la creación de sinergias y el enriquecimiento recíproco y favoreciendo la incorporación de novedades metodológicas de aprendizaje con carácter transdisciplinar.

12. La mejora de la implementación de estos proyectos requiere la colaboración de la Universidad con otras instituciones y la existencia de protocolos internos y de mecanismos de coordinación (calendarios sincronizados con el curso académico de las universidades, comisiones mixtas de seguimiento, etc.).

13. Sería interesante realizar un proceso de monitorización institucional de los proyectos desarrollados, recopilando y difundiendo tanto la información relativa a las actividades llevadas a cabo por el profesorado como el impacto derivado de las experiencias, para favorecer la difusión de sus resultados y contribuir a la diseminación de los logros y a la institucionalización del ApS. 


\section{Referencias}

Arancibia, S., de la Vega, L. F., Denis, A., y Saball, P. (2015). Evaluación de Programas sociales: un enfoque multidisciplinario. Revista del LLAD. Reforma y Democracia, (63), 99-126.

ARmijo, M. y Bonnefor, J. C. (2005). Indicadores de desempeño en el sector público. Santiago de Chile: Comisión Económica para América Latina y el Caribe.

AsENJo RuIz, C. (2016). Guía para el diseño, gestión y utilización de evaluaciones de programas y políticas públicas. Documento de Trabajo 45. Madrid: Programa Programa EUROsociAL.

BatLle, R. y EscodA, E. (coordinación) (2019). Cien buenas prácticas de Aprendizaje-Servicio. Inventario de experiencias educativas con finalidad social. Madrid: Santillana.

BECK, C. T. (2001) Caring within nursing education: a metasynthesis. Journal of Nursing Education, 40, 101-109.

BlanCHEt, T., BISWAS, H., ZAMAN, A. y LUCKY, M. A. (2018): From risks to rights: evaluation of a training programme for women aspiring to migrate for work. Dhaka, Bangladesh: SANEM Publications. Recuperado de https://www.Ishtm.ac.uk/files/ swift-bangaldesh-evaluation-report-2018.pdf

Cabrera-Cuevas, J. (2018). Creatividad e innovación a través de una propuesta de ApS en la formación universitaria Jessica Cabrera. Actas del IX Congreso Nacional ylEuropeo de Aprendizaje-Servicio en Educación Superior. Madrid, pp. 220-221.

CAMPO CANO, L. (2015). Evaluar para mejorar los proyectos de aprendizaje servicio en la universidad. RIDAS, Revista Iberoamericana de Aprendizaje y Servicio, 1, 91-111. doi.org/10.1344/RIDAS2015.1.6

CONEVAl. Consejo Nacional de Evaluación de las Poúticas de Desarrollo Social (2013). Manual para el diseño y la construcción de indicadores. Instrumentos principales para el monitoreo de programas sociales en México. México D.F.: CONEVAL.

Delahunty, J., O'Shea, S. y Stone, C. (2015). I 'feel' like I am at university even though I am online. Exploring how students narrate their engagement with higher education institutions in an online learning environment. Distance Education, 36(1), 41-58. doi.org/10.1080/01587919.2015.1019970 
Departamento Administrativo de Función Pública (2012). Guía para la construcción de indicadores de Gestión. Bogotá DC.: Departamento Administrativo de Función Pública.

Donoso, Y., Luna González, E. y Velasco Martínez, A. (2012). Violencia: Tolerancia Cero. Guía de evaluación para las intervenciones en violencia de género. Barcelona: Obra Social de la Caixa.

FINFGELD, D. L. (2003). Metasynthesis: The state of the art-So far. Qualitative Health Research, 13, 893-904.

Folgueiras Bertomeu, P., luna González, E. y Puig Latorre, G. (2013). AprendizajeServicio. Estudio del grado de satisfacción de estudiantes universitarios. Revista de Educación, 362, 159-185. Recuperado de http://www.revistaeducacion. educacion.es/doi/362_157.pdf

Francisco Amat, A. y Moliner Miravet, L. (2010). El Aprendizaje Servicio en la Universidad: una estrategia en la formación de ciudadanía crítica. REIFOP. Revista Electrónica Interuniversitaria de Formación del Profesorado, 13 (4), 69-77. Recuperado de http://www.aufop.com

Furco, A. (2004). El impacto educacional del Aprendizaje-Servicio ¿Qué sabemos a partir de la investigación? University of California-Berkeley. Recuperado de https://roserbatlle.files.wordpress.

García Gómez, T. (2011). Aportaciones ciudadanas desde el aprendizaje servicio: universidad, escuela y comunidad conectadas. Revista Interuniversitaria de Formación del Profesorado, 25(2), 125-141.

García GutiérRez, J., Ruiz Corbella, M. y del Pozo, A. (2020). Innovación y aprendizaje-servicio virtual: elementos para una reflexión basada en la experiencia. RIDAS, Revista Iberoamericana de Aprendizaje Servicio, 9, 62-80. doi.org/10.1344/ RIDAS2020.9.4

GoBierno VAsCo (S/F). Guía de evaluación de políticas públicas del Gobierno Vasco. Dirección de Coordinación, Álava: Dirección de Innovación y Administración Electrónica.

González Rabanal, M. C. (2021). El futuro del Aprendizaje-Servicio. Una aproximación desde la experiencia. Valencia: Tirant lo Blanch. 
González Rabanal, M. C. y Martínez Quintana, V. (2020). ¿Por qué estudiar un Máster en la UNED? Evaluación de la motivación de los alumnos de Postgrado. Madrid: Universitas.

Halcomb, E. y Hickman, L. (2015). Mixed Methods Research. Nursing Standard: promoting excellence in nursing care. Faculty of Science, Medicine and Health Papers: part A. 2656. doi.org/10.7748/ns.29.32.41.e8858

Jameson, J., MAsterman, E. y Walker, S. (2009). Capturing teachers' experience of learning design through case studies. Distance Education, 30(2), 223-238. doi. org/10.1080/01587910903023207

Jara Romero, P. y Romero Felip, A. (2009). Escala de evaluación del tipo y fase de la violencia de género (eetfvg). Jornades de Foment de la Investigació. Castellón, de la Plana: Universitat Jaume I.

Karunanayaka, S. P., Naidu, S., Rajendra, J. C. N. y Ratnayake, H. U. W. (2015). From OER to OEP: shifting practitioner perspectives and practices with innovative learning experience design. Open Praxis, 7(4), 339-350. doi.org/10.5944/ openpraxis.7.4.252

KISS, L. y ZIMMERMAN, C. (2019). Human trafficking and labor exploitation: Toward identifying, implementing, and evaluating effective responses. PLoS Med 16 (1). doi.org/10.1371/journal.pmed. 1002740

KLIKSBERG, B. y RiberA, M. (2007). Hacia un diseño de un sistema de monitoreo y evaluación de Programas. Capital social movilizado contra la pobreza, pp. 129-164. Buenos Aires: Consejo Latinoamericano de Ciencias Sociales de Comunidades Especiales de Puerto Rico-UNESCO.

London School of Hygiene and Tropical Medicine (2018). Human trafficking and modern slavery: New insights for policy and programmes. Emerging findings from Study on Work in Freedom Transnational (SWiFT) Evaluation. Asia Regional Briefing Note 1. Recuperado de https://www.Ishtm.ac.uk/swift-asia-regional-briefing.pdf

LUKEBCHUK, A. (2016). Themes at the intersections of theory and practice in online and blended education. Distance Education, 37(1), 130-136. doi.org/10.1080 /01587919.2016.1158771

Martín Sandoval de Escurdia, J. y Richard Muñoz, Ma . P. (2003). Los indicadores de evaluación del impacto de programas. México: Servicio de Investigación y Análisis. División de Política Social. 
Martínez, V., Rodríguez, R. Ma., Marco, M $^{a}$., y Macías, B. (2020). Percepciones del alumnado universitario sobre el aprendizaje-servicio como herramienta para su desarrollo personal y profesional. RIDAS, Revista lberoamericana de Aprendizaje y Servicio, 9, 81-101. doi.org/10.1344/RIDAS2020.9.5

Mayor Paredes, D. (2020). Aprendizaje-Servicio como estrategia metodológica para impulsar procesos de educación expandida. Multidisciplinary Journal of Educational Research, 10(1), 48-75. doi.org/10.4471/remie.2020.4562

Mendía Gallardo, R. (2008). El ApS, una metodología para el desarrollo de la competencia social y ciudadana. Monografías Escuela, 3, 6-7.

Ministerio de Mujer y Desarrollo Social (2007). Monitoreo y Evaluación de Programas Sociales, Lima: Dirección de Promoción, Asistencia Técnica y Capacitación.

MONDRAGón PÉREZ, A. (2002). ¿ Qué son los indicadores? Notas Revista Información y Análisis, 19, 52-58. México: Asesoría de la Oficina de la Presidencia del Instituto Nacional de Estadística, Geografía e Informática.

MORIN, L. y WAYSDORF, S. (2011-12). The Service-Learning Model in the Law School Curriculum. New York School Law Review, 56 (2), 561-616.

Navarro Rodríguez, S. R. y Larrubia Vargas, R. (2006). Indicadores para medir situaciones de vulnerabilidad social. Bioética. Estudios de Arte, Geografía e Historia, 28, 485-506.

Niño Martínez-Castro, C. y Macorra Barroso. Ma A. (2013). Guía para el seguimiento y evaluación de proyectos sociales. Cayoacán: Handel Mayer.

OECD-European Commission (2008). Handbook on Constructing Composite Indicators.Methodology and User Guide, París: OECD.

PICADO XINIA, J. A. (1989). Las metodologías de evaluación para programas sociales: Una necesidad en Costa Rica. Revista Centroamericana de Administración Pública, 17, 85-104.

PuIG RoviRA, J. M. (2009). Aprendizaje-Servicio: Educación y compromiso cívico. Barcelona: Crítica y Fundamentos.

Puig, J. M., Batlle, R., Bosch, C. y Palos, J. (2007). Aprendizaje-Servicio. Educar para la ciudadanía. Barcelona, España: Editorial Octaedro. Recuperado de 
http://educacion.wke.es/agendaonline/Admin/Upload/2816/aprendizaje\%20 servicio\%20muestra.pdf

Puig Rovira, J. M. y Palos Rodríguez, J. (2006). Rasgos pedagógicos del Aprendizaje-Servicio. Cuadernos de Pedagogía, 357, 60-63.

Roberts, J., Kigotho, M., y StagG, A. (2018). Expanding Horizons in Open and Distance Learning. Distance Education, 39(1), 1-3. doi.org/10.1080/0158791 9.2018.1439367

RODRíGUeZ IZQUIERDO, R. Ma. (2020). Aprendizaje Servicio y compromiso académico en Educación Superior. Revista Psicodidáctica, 25(1), 45-51. doi.org/10.1016/i. psicod.2019.09.001.

RuMBLE, G. (2007). Student support in distance education in the 21 st century: Learning from service management, Distance Education, 21(2), 216-235. doi.org/ $10.1080 / 0158791000210202$

Salam, M., Awang Iskandar, D. N., Ibrahim, D. H. A. y Farooq, M. S. (2019). Technology integration in service-learning pedagogy: A holistic framework. Telematics and Informatics, 38, 257-273. Recuperado de https://www.sciencedirect.com/ science/article/abs/pii/S073658531830354X

Sánchez Gómez, M. C., Martín García, A. V. y Palacios Vicario, B. (2015). Indicadores de violencia de género en las relaciones amorosas. Estudio de caso en adolescentes chilenos. Pedagogía Social. Revista Interuniversitaria, 26, 85-109. Recuperado de http://www.upo.es/revistas/index.php/pedagogia_social/

Secretaría de Finanzas y Administración (2015). Manual para la construcción de indicadores de desempeño. Estado de Hidalgo: Unidad Técnica de Evaluación del Desempeño.

Seider, S. C., Susan, G. y Rabinowicz, S. (2012). The Impact of Community Service Learning Upon the Expected Political Voice of Participating College Students. Journal of Adolescent Research, 27 (1), 44-77. doi.org/10.1177/0743558410391261

Suzanne, B., Cashman, ScD., DaSarena, D. y Seifer M. D. (2008). Service-Learning: An Integral Part of Undergraduate Public Health. American Journal of Preventive Medicine, 35 (3), 273-278. doi.org/10.1016/i.amepre.2008.06.012 
TAPIA, N. (2007). El Aprendizaje-Servicio en las Organizaciones de la Sociedad Civil. En AAVV, Antología 1997-2007. Seminarios internacionales Aprendizaje y Servicio Solidario. pp. 74-98. Buenos Aires: MECY. Recuperado de https:// infanciayjuventudsc.files.wordpress.com/201 1/06/antologc3ada-1997-2007-seminarios-internacionales-aprendizaje-y-servicio-solidario.pdf

TAPLIN, M. (2000). Problem-based learning in distance education: Practitioners' beliefs about an action learning Project. Distance Education, 21 (2), 278-299. doi. org/10.1080/0158791000210206

TODHUNTER, B. (2013). LOL -limitations of online learning- are we selling the open and distance education message short? Distance Education, 34(2), 232-252.

Tribunal Supremo de Elecciones de Costa Rica. (2017). Guía Metodológica para la elaboración de indicadores. Resumen ejecutivo. Costa Rica: Tribunal Supremo de Elecciones de Costa Rica. Dirección Ejecutiva. Área de Planificación Institucional.

\section{Anexo}

Resultados del cuestionario de satisfacción que han realizado los estudiantes, disponible en https://forms.gle/rje4GQAeExSTLcQeA

¿En cuál de las siguientes asignaturas estás matriculado?

5 respuestas

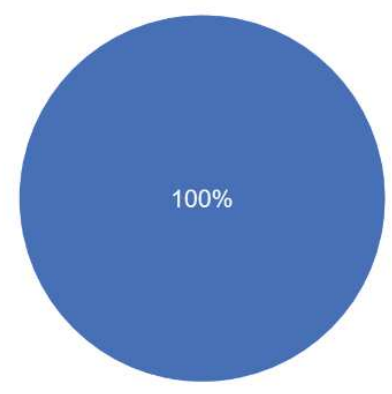


Sexo

5 respuestas

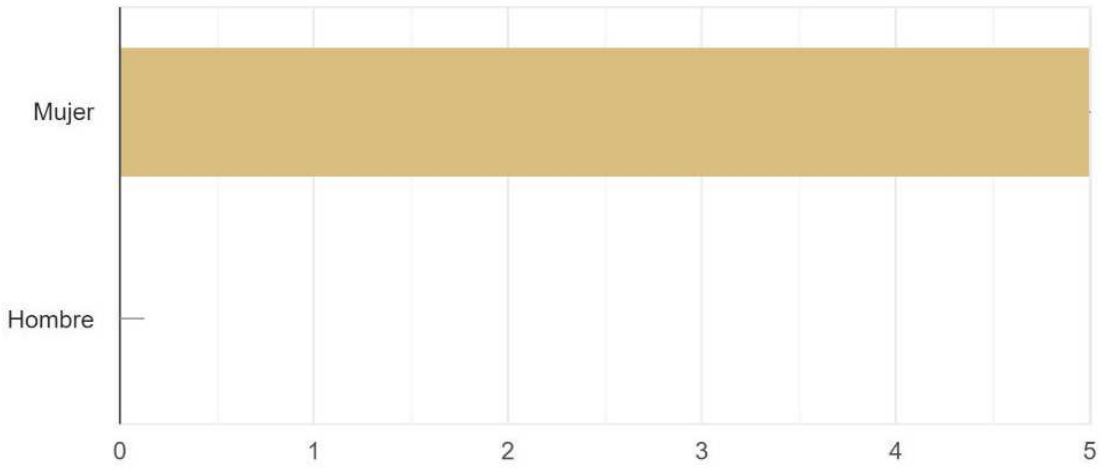

\section{Edad}

5 respuestas

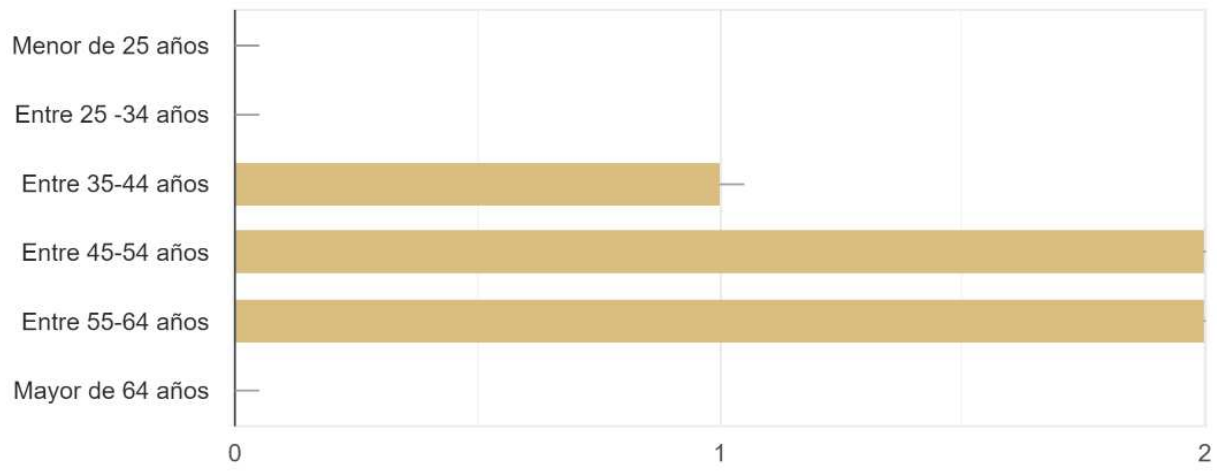

\section{Nacionalidad}

5 respuestas

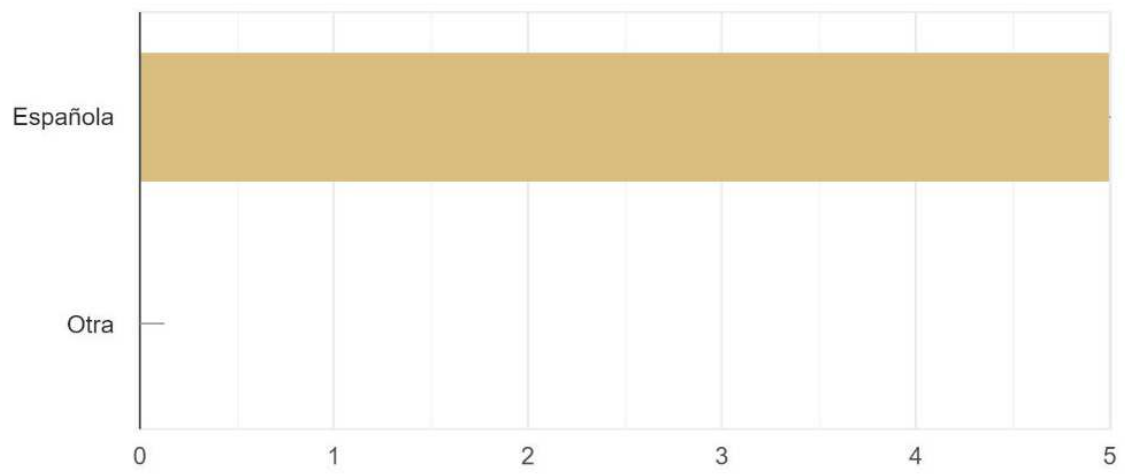


En caso de que seas de otra nacionalidad especifica, por favor, de qué pais. 2 respuestas

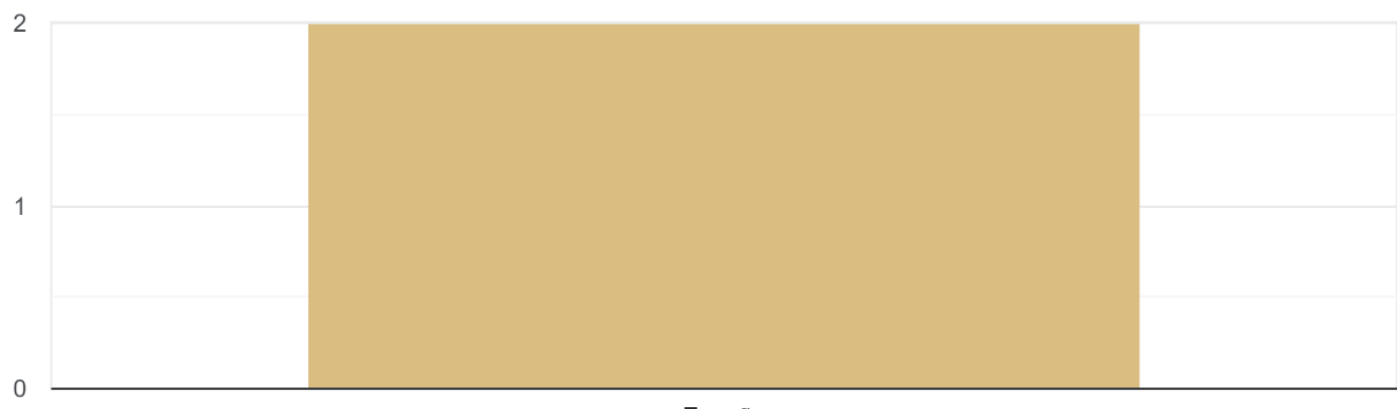

España

\section{Situación laboral}

5 respuestas



\section{Estado civil}

5 respuestas

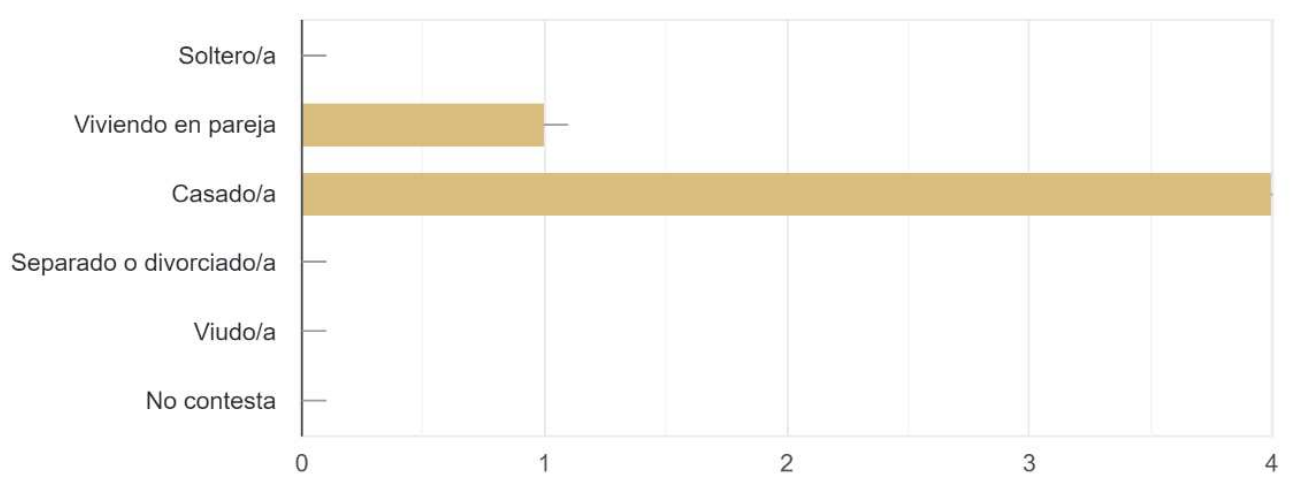


Nivel del estudios

5 respuestas



Licenciatura

Grado

Postgrado

Doctorado

- FORMACION PROFESIONAL

FORMACION PROFESIONAL II

Para empezar ¿nos podrías decir, por favor, cómo has sabido de la existencia de este Grado? 5 respuestas

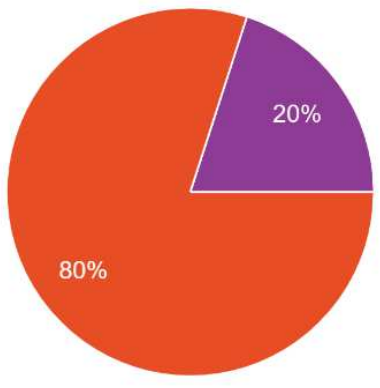

Por medios de comunicación: prensa, radio y tv

Por la web de la UNED

Amigos y conocidos

En un centro asociado de la UNED

Por comunicación de la profesora de la asignatura

¿ Cuál fue el motivo para cursar los estudios de Grado en la UNED? Valora los siguientes aspectos de 1 a 5 siendo 1 menor importancia y 5 mucha importancia

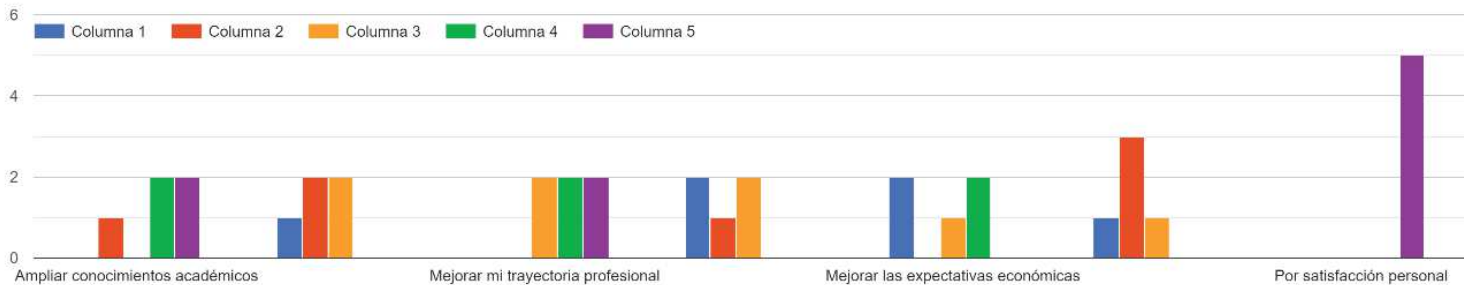

De los motivos que te llevaron a participar en el APS (UNED 2019-2020) valora los siguientes aspectos de 1 a 5, siendo 1 menor importancia y 5 mucha importancia

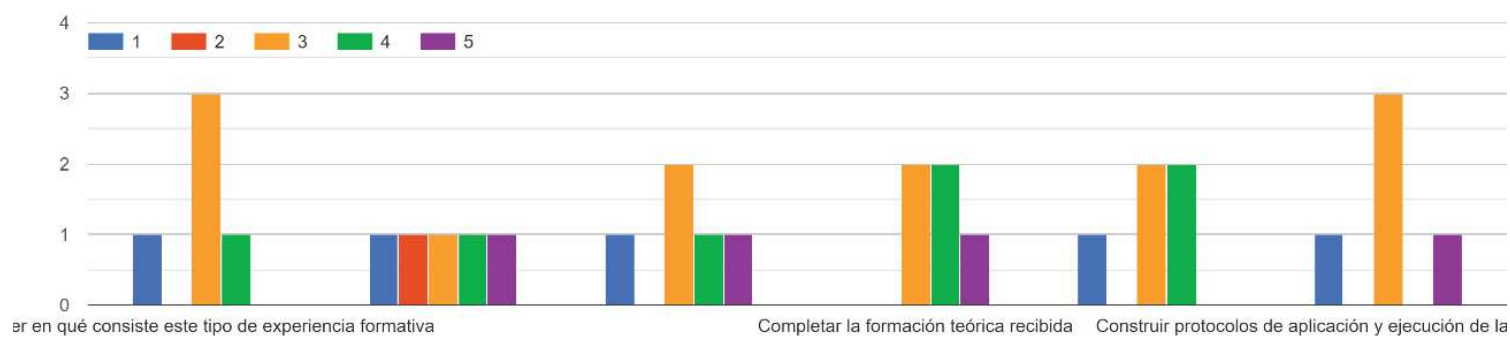


Especifica, si lo deseas, otros aspectos que consideres de interés no recogidos en la anterior pregunta [5 respuestas]:

- Es bastante completo.

- No deseo realizar aportación.

- Las motivaciones están ya recogidas en el apartado.

- Primero curiosidad, después el poderlo aplicar a la administración, si apruebo las oposiciones.

- Mucha curiosidad sobre un mundo que no conozco.

¿Crees que el proceso de selección es adecuado?

5 respuestas

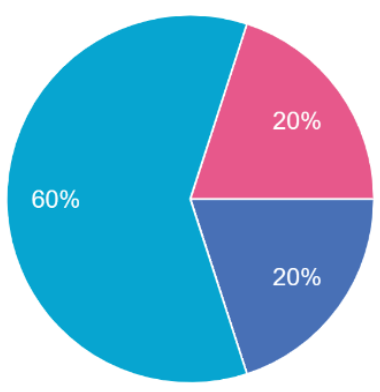

Si

Sí, pero han tardado demasiado en confirmarme que estaba seleccionado...

No

No, el hecho te tener que enviar una carta de motivación no me parece lo...

Creo que sería más adecuado seleccionar a los alumnos por su expe...

No tengo claros cuáles han sido los re...

Sí, pero el proceso de selección se ha...

Indica, si es posible, qué requisitos de selección para tu participación en la experiencia APS consideras imprescindibles [5 respuestas]:

- Desconozco cuales han sido los criterios por los que he sido elegida, no obstante, el carácter voluntario a la participación y la consulta previa deberían ser imprescindibles.

- Motivación.

- La motivación para la participación y la voluntariedad.

- Hacer un pequeño test de motivación.

- Motivación y formación relacionada.

Indica, si es posible, qué requisitos de selección para tu participación en la experiencia APS consideras prescindibles [5 respuestas]:

- No lo se.

- Experiencia previa.

- El expediente académico.

- El expediente académico puede ayudar, pero la motivación es más importante.

- La edad. 
Valora los siguientes aspectos de las actividades del Proyecto Aprendizaje-Servicio, siendo 1 poco adecuado y 5 muy adecuado



En caso afirmativo, especifica cuáles [5 respuestas]:

- Mi respuesta ha sido negativa.

- Nada que añadir.

- La respuesta ha sido negativa.

- No tengo las lecturas, no sé dónde encontrarlas, ¿̇cómo puedo hacer el trabajo?

- He contestado una respuesta que no hacía falta justificar, creo.

¿Añadirias alguna actividad más?

5 respuestas



En caso afirmativo, especifica cuáles [5 respuestas]:

- Mi respuesta ha sido negativa.

- Un acercamiento a la actividad a través de la persona adecuada en el Ayuntamiento.

- La respuesta ha sido negativa.

- Un plan de trabajo.

- Algo práctico, una visita a un lugar donde se lleva a cabo la APS. 
Añade si existen, según tu criterio, posibles sugerencias de mejora [5 respuestas]:

- No.

- Formar un "equipo de trabajo virtual" entre el director de área del ayuntamiento y los alumnos participantes, a fin de configurar las nociones básicas del trabajo a realizar y reparto del mismo.

- Mayor claridad a la hora de seleccionar a los alumnos.

- Creo que la carga de documentación es ingente, sobre todo en pleno periodo de exámenes.

- Más tiempo, creo que compaginarlo con estudios sobre todo al final de un grado se hace difícil.

¿La realización de las tareas te ha supuesto mucha carga adicional de trabajo?

5 respuestas

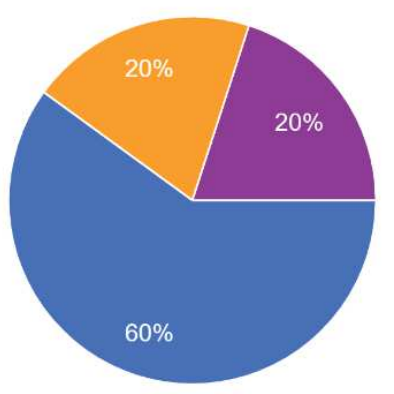

Si

No

Si, pero reconozco que son

fundamentales para el aprendizaje en el proyecto APS

No, las tareas que se piden no son demasiadas y se pueden hacer de manera amena

No, pero coincidiendo tan cercano a los exámenes, no le he dedicado el tiemp...

¿Piensas que el esfuerzo ha merecido la pena?

5 respuestas

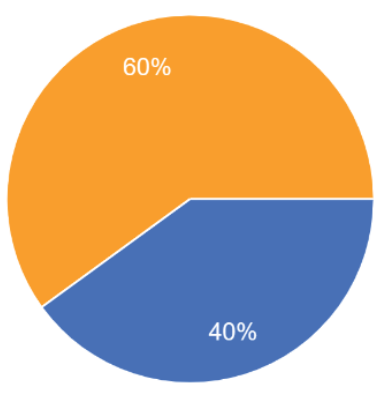

Sí

No

Tal vez 
Sea cual sea la elección realizada en la pregunta anterior, nos gustaría saber tus razones para tal elección [5 respuestas]:

- Cuando me asignan una tarea la cumplo.

- El tipo de proyecto se sale completamente de mi área de especialización, y habiéndome acercado a esta materia por primera vez a través del estudio de la asignatura, me resultaba muy interesante vivir de cerca cómo se gestaban desde dentro este tipo de proyectos.

- La prueba hay que plantearla con más tiempo, diciembre me parece tarde.

- Mucha carga para poca explicación o muy superficial de ella.

- Aquello que he aprendido se suma a mi "cultura".

Apoyo del equipo docente. Valora los siguientes aspectos con una puntuación de 1 a 5 , siendo 1 poco apoyo y 5 mucho apoyo



Sugerencias de mejora respecto a la pregunta anterior [5 respuestas]:

- No ha habido demasiado contacto entre alumnos y profesorado.

- El equipo docente ha sido el mejor apoyo durante esta experiencia, siempre dispuestos a ayudar. Nada que añadir pues en este punto.

- Explicar más detenidamente lo que se espera conseguir con el proyecto, dar pautas para realizar las pruebas.

- Ha habido poca interacción, quizás de ambos.

- Modificar el binomio trabajo/tiempo para realizarlo(dependiendo de la carga estudiantil). 
¿Consideras que los estudios en la UNED son más fáciles de realizar que en una universidad presencial? Responde si estás muy de acuerdo, de ...rdo o nada de acuerdo con las siguientes frases:



Nos gustaría conocer tu valoración de las posibles ventajas de enseñanza a distancia frente a la presencial. Señala muy de acuerdo, de acuerdo, ni ...erdo con cada una de las siguientes afirmaciones:

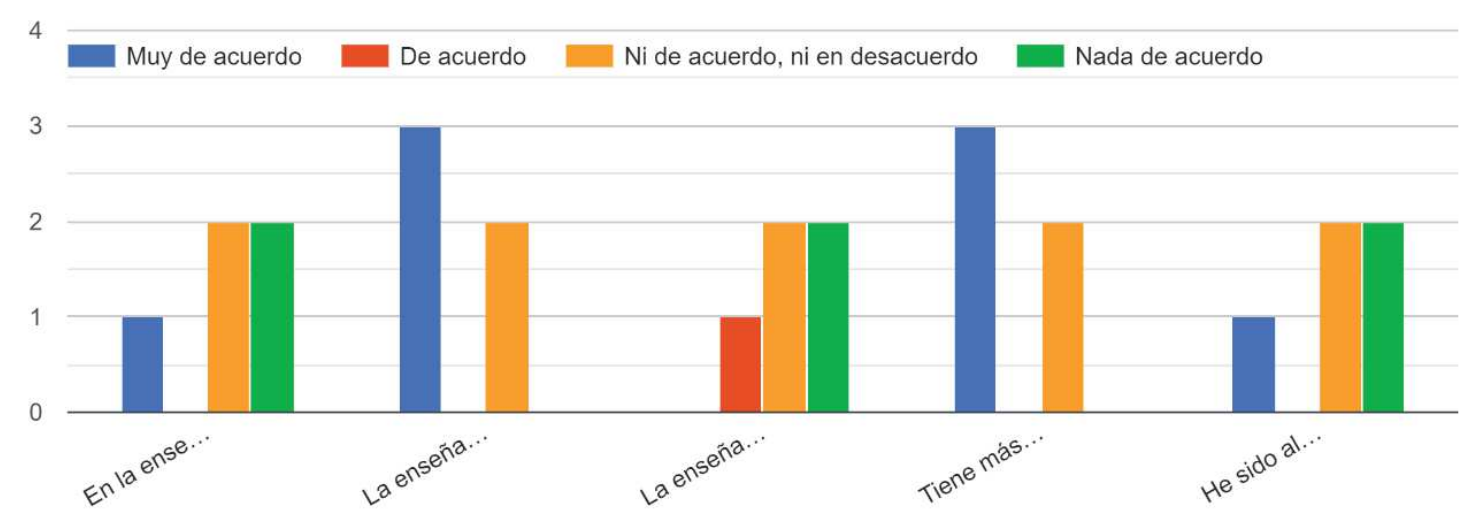

\section{Otros factores que deseas hacer constar [5 respuestas]:}

- Ninguno.

- En algunas asignaturas se abandona al alumno a su suerte, lo que en la práctica supone que compre el libro y se enfrente solo a la asignatura, no habiendo clases, y en muchos casos ni respuestas de dudas antes del examen. Hay una gran variabilidad entre el profesorado, algunos se preocupan por el alumno y resolver las dudas, y otros profesores en la práctica son inexistentes.

- El nivel de exigencia es muy alto y los temarios muy extensos.

- La UNED es dura, y en algunas asignaturas aún mantiene criterios y material como si fuera presencial.

- La UNED es una carrera de fondo y tu peor enemigo eres tú mismo. 
¿Qué opinas de la ESTRUCTURA del Proyecto Aprendizaje-Servicio?

5 respuestas
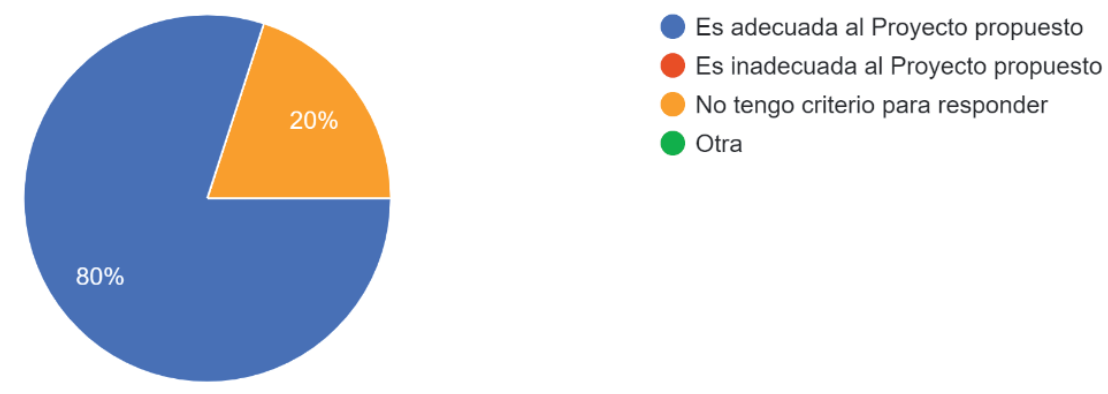

Cuáles serían las mejoras que incluirías, con carácter general, sobre la ESTRUCTURA del Proyecto de Aprendizaje-Servicio? [5 respuestas]:

- No incluiría mejoras.

- Separación entre la realización del proyecto y el calendario de exámenes.

- No incluiría mejoras.

- Algún contacto con ONG y Servicios Sociales.

- No sabría contestar, es el primero en el que participo.

¿Cuáles serían las mejoras que incluirías, con carácter general, sobre el CONTENIDO del Proyecto de Aprendizaje-Servicio? [5 respuestas]:

- No incluiría mejoras.

- Plataforma de más fácil acceso.

- Me ha parecido adecuado.

- Un seguimiento a los 6 meses y a los 12 y 24.

- El poder tener información a posteriori.

¿Cuáles serían las mejoras que incluirías, con carácter general, sobre el desarrollo del Proyecto de Aprendizaje-Servicio? [5 respuestas]:

- Es completo.

- Formar un "equipo de trabajo virtual" entre el director externo del proyecto y los alumnos participantes, a fin de indicar expectativas y tareas a realizar.

- Como ya he indicado, más explicaciones sobre cómo realizarlo o lo que se espera conseguir con ello.

- Extrapolarlo a estudios de FP de la rama de servicios sociales, como una asignatura práctica.

- Que no acabara aquí, poder realizar otros, no tienen que ser de la misma temática. 
¿Piensas que este tipo de Aprendizaje-Servicio debería aplicarse en otras asignaturas? 5 respuestas
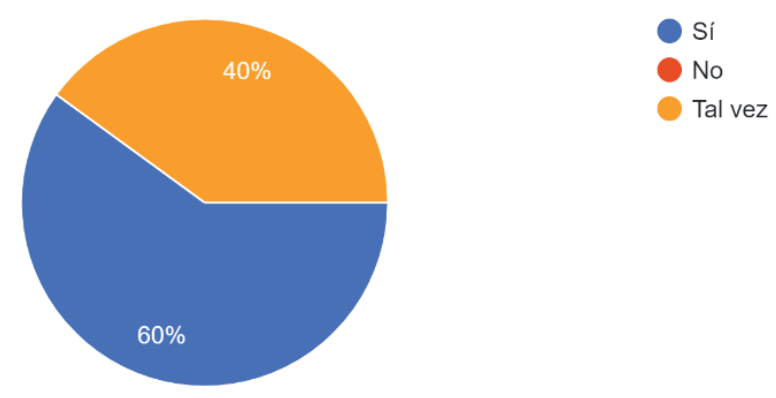

En caso afirmativo, especificar cuáles [4 respuestas]:

- Todas las asignaturas deberían poder ofrecer una parte práctica, pues ayuda al alumno a acercarse al trabajo de campo.

- No todas las asignaturas son susceptibles de platear este tipo de proyectos.

- Todas aquellas en las que se relacione la gestión pública de recursos y en las áreas de recursos humanos.

- A casi todas.

¿Cuál es tu valoración global de esta experiencia?

5 respuestas

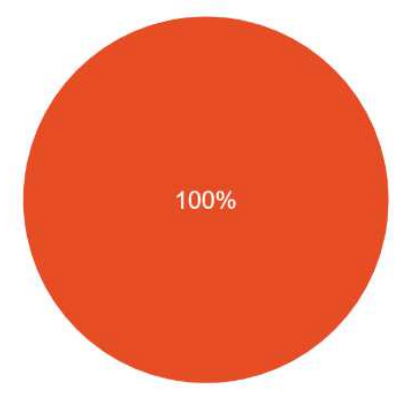

Me ha parecido una experiencia muy

enriquecedora

Es una experiencia positiva en general

No es como yo me lo esperaba

Es una experiencia que considero que podría mejorarse

No tengo criterio para responder

Otra

¿Qué aspectos destacarías como más positivos de tu experiencia en este proyecto? (Indicar las razones) [5 respuestas]:

- Los conocimientos que adquieres.

- La implicación del profesorado y el conocimiento de primera mano de la materia.

- Los conocimientos conseguidos.

- La novedad, me ha resultado una experiencia de la que no sabía su existencia.

- El conocer actividades que no sabía que existían. Me ha parecido interesante. 
¿Qué aspectos destacarías como más negativos de tu experiencia en este proyecto? (Indicar las razones) [5 respuestas]:

- La carga de trabajo unida al estudio del grado y a las cargas laborales, familiares, etc. que supongo tenemos todos los alumnos.

- La falta de tiempo por la cercanía con los exámenes.

- La carga de trabajo, el sacrificio personal.

- Se necesitaría más tiempo para poder llevarla a cabo en condiciones, saber resultados,etc...

- El no haber sabido interpretar mejor aquello que se me pedía, por inexperiencia.

Si lo deseas, puede añadir algún comentario que te sugiera este cuestionario y/o que debería incorporarse al mismo en futuras ediciones del Proyecto [ 5 respuestas]:

- No, gracias.

- Nada que añadir.

- Muy extenso. Lo cumplimenté una vez y al remitirlo hubo problemas y he tenido que repetirlo.

- Una consulta a los estudiantes a los 6 meses y al cabo de 1 año para saber si en su vida cotidiana han podido colaborar en alguna APS.

- Es interesante la experiencia, jabrirla a más estudiantes!

Muchas gracias por ayudarnos a mejorar la oferta de los Grados, si quieres, puedes dejar un comentario final [5 respuestas]:

- Gracias por la selección y espero haber cumplido con las expectativas.

- Globalmente valoro muy positivamente este tipo de formación/aprendizaje.

- En relación con los grados, la evaluación continua debería premiar y no castigar el esfuerzo de los estudiantes. Si a la carga de estudio le sumamos los trabajos a realizar como evaluación continua, a quien decida seguir este tipo de sistema, debería serle tenido en cuenta como algo positivo y no solo para mejorar nota. Incluso en algunas asignaturas puede dar lugar a una rebaja en las notas, vamos que no anima mucho a seguir este sistema.

- Gracias por haberme dejado participar, es enriquecedora esta experiencia.

- Una experiencia muy positiva, habría que darla a conocer más. 